\title{
ESTATUTO PESSOAL NO DIREITO INTERNACIONAL PRIVADO: EVOLUÇÃO E PERSPECTIVAS NO BRASIL
}

\author{
PERSONAL STATUTE IN THE PRIVATE INTERNATIONAL LAW: EVOLUTION AND PERSPECTIVES
}

IN BRAZIL

André de Carvalho Ramos*

Resumo:

O presente artigo foca a situação do estatuto pessoal no Direito Internacional Privado. O estudo apresenta a evolução no Brasil das regras de conexão tradicionais sobre o tema, como a lei da nacionalidade e a lei do domicílio, bem como aborda a possibilidade de introdução de regras abertas e flexíveis.

Palavras-chave: Direito Internacional Privado. Estatuto Pessoal. Nacionalidade. Domicílio.

\begin{abstract}
:
The paper aims to analyze the personal statute in the private international law in Brazil, showing the main connections factors, as the law of nationality or law of domicile, investigating the possibility of flexible and open connection rules.
\end{abstract}

Keywords: Private International Law. Personal Statute. Nationality. Domicile.

Introdução

O presente artigo aborda um dos temas mais tradicionais do Direito Internacional Privado (DIPr), que vem a ser o estatuto pessoal. De fato, entre os mais diversos fatos transnacionais que podem ser regulados pelo DIPr, destacam-se os que se referem ao estatuto pessoal, que consiste no conjunto de atributos referentes à individualidade jurídica. Para Tenório, a expressão "estatuto pessoal" engloba "as relações pessoais do indivíduo, desde o nascimento até a morte, abrangendo sua situação no meio familiar, ou independente dele, mas em relações com outras pessoas". ${ }^{1}$

$\mathrm{O}$ estatuto pessoal refere-se, em geral, à pessoa física e engloba a regulamentação sobre estado da pessoa, capacidade, filiação, nome, pátrio poder, casamento, dissolução do matrimônio, união homoafetiva, morte, alimentos, adoção, entre outros temas.

\footnotetext{
Professor Associado do Departamento de Direito Internacional e Comparado da Faculdade de Direito da Universidade de São Paulo. Professor dos Programas de Pós-Graduação em Direito Internacional e em Direitos Humanos da mesma instituição (CAPES 6). Livre-Docente e Doutor em Direito Internacional pela Faculdade de Direito da Universidade de São Paulo. Membro da Asociación Americana de Derecho Internacional Privado (ASADIP). Membro da Sociedade Brasileira de Direito Internacional (SBDI).

1 TENÓRIO, Oscar. Direito internacional privado. 11. ed. Rio de Janeiro: Freitas Bastos, 1976. v. 1, p. 408.
} 
Pela sua abrangência, o estatuto pessoal revela, no âmbito do DIPr, a escolha sobre o vínculo de determinado indivíduo com um ordenamento jurídico. Essa escolha não é neutra e gera impactos. Determinado Estado que opta (por lei interna ou por ratificação de tratado de DIPr) pela lei da nacionalidade toma uma importante decisão que acelera a aplicação do direito estrangeiro em seu país, já que vivemos em um mundo globalizado, com fortes fluxos de migrantes (com suas nacionalidades distintas). Caso opte pelo domicílio, esse Estado hipotético gerará debates e eventuais conflitos sobre como definir o que vem a ser um "domicílio" ou mesmo como eliminar as dúvidas na hipótese de coexistência de domicílios.

Essas discussões devem ser renovadas à luz das novas dimensões do Direito Internacional Privado do século XXI, que busca superar o antigo cisma entre a "lei da nacionalidade" e a "lei do domicílio". Para tanto, o presente artigo focará a evolução do tratamento do tema do estatuto pessoal no Brasil, desde a independência até os dias de hoje. À guisa de conclusão, analisaremos as perspectivas da temática, com ênfase no possível uso do critério de conexão da residência habitual ou ainda do princípio da proximidade.

\section{A disputa clássica}

A regulação do estatuto pessoal foi disputada, a partir da fase clássica do Direito Internacional Privado, por duas regras de conexão principais: a lei da nacionalidade e a lei do domicílio. ${ }^{2}$ Anteriormente, na fase iniciadora (ou fase estatutária), a própria noção de nacionalidade era precária, em um mundo europeu caracterizado pelas lutas entre monarquias dinásticas e sob a influência do Papado. ${ }^{3}$ Assim, as diferentes Escolas estatutárias adotavam a lei do domicílio, para a regência do estatuto pessoal. ${ }^{4}$

No século XIX, a consolidação do conceito da nacionalidade ${ }^{5}$ como um dos principais vetores do Estado influenciou também o Direito Internacional Privado. O marco pioneiro foi o Código Civil de Napoleão, que, em seu art. $3^{\circ}$, estipulou que as leis

2 Sobre a fase clássica do Direito Internacional Privado, ver CARVALHO RAMOS, André de. Evolução histórica do direito internacional privado e a consagração do Conflitualismo. Revista de la Secretaría del Tribunal Permanente de Revisión, ano 3, n. 5, p. 423-446, Marzo 2015.

3 Sobre as fases precursora e iniciadora (estatutária) do Direito Internacional Privado, ver CARVALHO RAMOS, André de. Evolução histórica do direito internacional privado e a consagração do Conflitualismo. Revista de la Secretaría del Tribunal Permanente de Revisión, a. 3, n. 5, p. 423-446, Marzo 2015.

$4 \quad$ PILLET, Antoine. Principes de droit international privé. Paris: Pedone/Allier Frères, 1903. Em especial p. 304. MACHADO VILLELA, Álvaro da Costa. Tratado elementar (teórico e prático) de direito internacional privado. Coimbra: Coimbra Editora, 1921. v. 1, p. 414.

5 Demonstrando que o conceito de nacionalidade não é atemporal, mas serviu aos esforços de unidade dos Estados europeus do século XIX, ver HOBSBAWM, Eric J. Nações e Nacionalismo. 5. ed. São Paulo: Paz e Terra, 2008. Em especial p. 11-61. 
concernentes ao estado e capacidade das pessoas regeriam os franceses mesmo quando residissem em país estrangeiro. ${ }^{6}$

Savigny, por seu turno, manteve a adesão à lei do domicílio, defendendo a continuidade de seu uso (comum entre os estatutários), com base em seus estudos sobre o Direito Romano e também em virtude da ampla aceitação da lei do domicílio.?

Também na fase clássica do DIPr, Mancini, no bojo do processo de unificação italiana, esforçou-se para consagrar o princípio da nacionalidade tanto no Direito Internacional Público quanto no DIPr. ${ }^{8}$ Para Villela, o uso da lei da nacionalidade para reger o estatuto pessoal no DIPr é justificado por ser a lei pessoal uma função da nacionalidade e, portanto, a lei pessoal competente deve ser a lei nacional. ${ }^{9}$

No choque das duas correntes, são comuns os seguintes argumentos e contra-argumentos, centrados nos seguintes tópicos:

(i) Estabilidade. Os adeptos da lei da nacionalidade apontam sua estabilidade, sendo um vínculo, em geral, permanente e conhecido, o que não acontece com o domicílio, sujeito a mudanças ao sabor da vontade do indivíduo. Os defensores da lei do domicílio, por sua vez, enfatizam a autonomia da vontade na fixação do domicílio, que seria mais próximo do verdadeiro centro de suas relações jurídicas (ao invés da nacionalidade, em geral imposta no nascimento). Ou seja, a lei do domicílio seria um vínculo jurídico e, consequentemente, mais apropriado ao DIPr e a nacionalidade, um vínculo político;

(ii) Coerência com a proteção diplomática. Os defensores da lei da nacionalidade usaram, analogicamente, o instituto da proteção diplomática do Direito Internacional Público, muito em voga na segunda metade do século XIX. Esse costume internacional trata da reparação de danos causados a estrangeiro pelo Estado de acolhida, em demanda apresentada pelo Estado patrial. Assim, tal qual a nacionalidade protege o indivíduo por meio da proteção diplomática, a lei da nacionalidade seria também um mecanismo de "proteção individual". Para os defensores da lei do domicílio, o tratamento dado ao estrangeiro domiciliado não teria porque ser, per se, menos protetivo do que o dado pela lei da nacionalidade;

(iii) Interesse do Estado de acolhida dos estrangeiros e efeito negativo da inflação do uso do direito estrangeiro. Esse argumento foi muito utilizado na América

\footnotetext{
6 MACHADO VILLELA, Álvaro da Costa. Tratado Elementar (teórico e prático) de Direito Internacional Privado. Coimbra: Coimbra Editora, 1921. v. 1, p. 416.

7 Ver SAVIGNY, Friedrich Carl von. Sistema do direito romano atual. Tradução de Ciro Mioranga (edição original de 1849). Ijuí: Ed. Unijuí, 2004. v. 8, §§ 358-359, p. 100-110.

8 MANCINI, Pasquale S., A nacionalidade como fundamento do direito das gentes (1851). In: Direito Internacional: coletânea. Ijuí: Ed. Unijuí, 2003. p. 35-86.

9 MACHADO VILLELA, Álvaro da Costa. op. cit., v. 1, p. 415.
} 
Latina, pelos seguidores da lei do domicílio. Sustentou-se que não interessa ao Estado de acolhida de imigrantes (como os da América Latina) manter a aplicação de direito estrangeiro (apontado pela lei da nacionalidade) por décadas, até que as novas gerações adquirissem a nacionalidade local. A lei da nacionalidade, então, dificultava a prestação jurisdicional (que tinha ainda de acompanhar a evolução do direito estrangeiro) e mantinha ainda diferenças normativas no seio da comunidade. Além disso, em vários casos, as correntes migratórias europeias para a América Latina eram concentradas em algumas regiões (italianos no sul e sudeste, alemães no sul, japoneses em São Paulo etc.), o que inflacionava ainda mais o uso do direito estrangeiro em alguns locais. Ironicamente, o Brasil imperial usou esse argumento (correntes migratórias) justamente para defender a lei da nacionalidade no Congresso de Direito Internacional Privado de Montevidéu (1878): para a diplomacia brasileira da época, a lei da nacionalidade seria um atrativo ao estrangeiro, que, teria a segurança jurídica necessária para, então, aceitar imigrar para novos países; ${ }^{10}$

(iv) Vantagem do melhor conhecimento da lei. Os defensores da lei da nacionalidade defendem seu uso pelo maior conhecimento da lei nacional e comunhão de valores do indivíduo com sua pátria de origem. Essa defesa desconsidera o papel da comunidade de acolhida e de sua função na promoção de direitos do estrangeiro;

(v) Vantagem da melhor integração do estrangeiro com a comunidade de acolhida. Esse argumento é utilizado pelos defensores da lei do domicílio, cujo uso integraria com maior velocidade os estrangeiros domiciliados, que seriam forçados a conhecer a legislação local (pelo uso da lei do domicílio) e, consequentemente, seriam mais conhecedores dos usos da comunidade de acolhida.

(vi) Maior coincidência entre a lei aplicável e a jurisdição. Os defensores da lei do domicílio sustentam a vantagem da unidade entre a jurisdição e a lei a ser aplicada. De fato, a maior parte dos litígios serão processados no Estado de domicílio dos interessados, de acordo com a tradicional regra de fixação da competência territorial do juízo: foro do domicílio do réu, ou, eventualmente, do autor. Caso o domicílio também seja a regra para a escolha da lei, haveria uma grande coincidência entre a lei que rege o processo e a lei a ser aplicada ao fato em litígio, aproximando a competência jurisdicional da competência legislativa. ${ }^{11}$ Para os defensores da lei da nacionalidade, não há nenhuma dificuldade ou contradição no fato de uma jurisdição nacional ser obrigada a aplicar direito estrangeiro;

\footnotetext{
10 Ver abaixo tópico sobre a lei da nacionalidade no Império brasileiro.

11 CASSIN, René. La nouvelle conception du domicile dans le règlement des conflits de lois. Recueil des Cours de l'Académie de Droit International de la Haye, n. 34, p. 659-809, 1930. Em especial p. 772.
} 
(vii) Dificuldades com situações especiais: mulheres casadas, apátridas, refugiados, sem domicílio. A defesa da lei da nacionalidade como uma lei estável, segura e acessível esbarrou na constatação de problemas práticos envolvendo a nacionalidade da mulher casada ${ }^{12}$ (superada por tratados e pela consolidação do Direito Internacional dos Direitos Humanos, cujas normas proíbem as distinções odiosas a favor do homem), apátridas e refugiados. Por sua vez, as mudanças de domicílio e mesmo situações pluridomiciliares ou ainda dos adômides (sem domicílio) geraram debates sobre a conveniência da substituição da lei do domicílio pela lei da "residência habitual";13

(viii) Universalismo. Os defensores da lei da nacionalidade no final do século XIX e primeiras décadas do século XX viam na lei do domicílio uma opção por um Direito Internacional Privado local ou particular. Já o uso da nacionalidade levaria o Direito Internacional Privado mais próximo do Direito Internacional Público, ou seja, mais próximo da ambição universalista e da essência do Direito Internacional Privado clássico, de uma comunidade homogênea de nações. Espínola e Espínola Filho, nesse sentido, palmilham esse caminho ao sugerir que "o sistema da lei nacional é o que melhor corresponde aos princípios que constituem o fundamento do direito internacional privado". ${ }^{14}$

Ocorre que, posteriormente, após a metade do século XX e XXI, a consolidação da proteção internacional dos direitos humanos faz com que a nacionalidade e os obstáculos ao estrangeiro (especialmente em um mundo no qual há inúmeras barreiras aos migrantes econômicos, com aumento da xenofobia) sejam adversários do novo universalismo, entendido agora sob o prisma da gramática dos direitos humanos, no qual todos são iguais, não importando origem ou nacionalidade. Nesse sentido, o vínculo jurídico do domicílio ou da residência habitual é igualitário, pois disponível tanto aos nacionais quanto aos estrangeiros em situação regular ou não.

$\mathrm{Na}$ doutrina do final do século XIX e início do século XX, rapidamente a lei da nacionalidade foi vitoriosa. Entre os internacionalistas, a grande maioria apoiou as ideias de Mancini, fazendo o Instituto de Direito Internacional (organização não governamental de cunho científico e acadêmico voltada ao Direito Internacional, criada em 1873 por Mancini, Carlos Calvo, Asser e outros) editar, em 1880, a Resolução de

12 Ver VALLADÃO, Haroldo. Conséquences de la différence de nationalité ou de domicile des époux sur les effets et la dissolution du mariage. Recueil des cours de l'Académie de Droit International de la Haye, n. 105, p. 69-171, 1962.

13 WINTER, L. I. de. Nationality or Domicile? The present state of affairs. Recueil des cours de l'Académie de Droit International de la Haye, n. 128, p. 347-503, 1969.

14 ESPÍNOLA, Eduardo; ESPÍNOLA FILHO, Eduardo. Tratado de direito civil brasileiro. Do direito internacional privado brasileiro: parte especial. Primeiro Tomo. Rio de Janeiro: Freitas Bastos, 1942. v. 8, t. 1, p. 182. 
Oxford sobre os princípios gerais em matéria de nacionalidade, capacidade, sucessão e ordem pública, consagrando a lei nacional (item VI da Resolução). ${ }^{15}$

Claro que nesse momento histórico (transição do século XIX e século $\mathrm{XX}$ ), além da bem-sucedida estratégica dos defensores da vinculação da lei nacional ao universalismo pretendido pelos internacionalistas de uma comunidade homogênea de nações do final do século XIX, a maior parte dos doutrinadores internacionalistas influentes era europeia (mesmo Carlos Calvo, argentino, viveu boa parte de sua vida em Paris, onde faleceu) e os Estados europeus viam a lei do domicílio como ameaça, equivalente ao rompimento dos laços com a comunidade de migrantes espalhada, em especial, na América Latina.

\section{A lei da nacionalidade no Brasil Imperial}

No Brasil independente, a Constituição de 1824 (art. 179, XVIII) determinou a elaboração de um Código Civil, na esteira das codificações europeias. O Direito Internacional Privado foi absorvido nas discussões sobre o novo Código Civil, seguindo a tradição europeia de tratar dos fatos transnacionais em Códigos ou em leis de introdução, segundo a matéria (Código Civil, Código Penal etc.) e não tratando de todas as espécies em uma única lei de Direito Internacional Privado.

Essa opção de tratar de todas as facetas cíveis e não-cíveis em um único diploma foi seguida por alguns tratados de Direito Internacional Privado, como, por exemplo, o Código Bustamante (Convenção Panamericana de Direito Internacional Privado, $\left.1928^{16}\right)$.

No caso brasileiro, a legislação de Direito Privado esparsa, vigente no Império, optou pela aplicação da lei da nacionalidade, como se vê no art. $3^{\circ}$ do Regulamento n. 737 de 1850 (referente a atos de comércio), pelo qual as "leis e usos comerciais dos países estrangeiros regulam as questões sobre estado e idade dos estrangeiros residentes no Império". ${ }^{17}$

Na Consolidação das Leis Civis (1858) do Império, na qual Teixeira de Freitas (contratado, em 1855, pelo Imperador para tal tarefa) condensou a legislação

15 Instituto de Direito Internacional, Resolução de 1880, Oxford, referente aos «Principes généraux en matière de nationalité, de capacité, de succession et d'ordre public». Item VI: «VI. L'état et la capacité d'une personne sont régis par les lois de 1'Etat auquel elle appartient par sa nationalité.» Grifo nosso. Disponível em: <http://www.idi-iil.org/idiF/resolutionsF/1880_oxf_01_fr.pdf $>$. Acesso em: 25 jan. 2015.

16 Ratificada pelo Brasil e incorporada internamente pelo Decreto n. 18.871, de 13 de agosto de 1929. O Código é imenso (437 artigos), divido em quatro livros: Direito Civil Internacional, Direito Comercial Internacional, Direito Penal Internacional e Direito Processual Internacional.

17 Disponível em: < http://www.planalto.gov.br/ccivil_03/decreto/Historicos/DIM/DIM737.htm>. Acesso em: 26 jan. 2015. 
vigente, ficou estabelecido no art. 408 que as "questões de estado e idade de estrangeiros residentes no Império, quanto à capacidade para contratar, serão também reguladas pelas leis e usos dos países estrangeiros." 18

Também os projetos e discussões sobre o novo Código Civil ainda na época do Império, adotaram a lei da nacionalidade, como se vê no chamado Projeto Nabuco (art. $35^{19}$ ) e no Projeto Felício dos Santos (art. $18^{20}$ ).

A exceção foi o Esboço de Teixeira de Freitas, ${ }^{21}$ que defendeu o uso da lei do domicílio (arts. 26 e 27). Nesse anteprojeto de Código Civil, Teixeira de Freitas optou pela lei do domicílio para a regência do estatuto pessoal. De acordo com o art. 26 “a capacidade, ou incapacidade (art. 25), quanto a pessoas domiciliadas em qualquer seção territorial do Brasil, ou sejam nacionais ou estrangeiras, serão julgadas pelas leis deste Código, ainda que se trate de atos praticados em país estrangeiro ou de bens existentes em país estrangeiro." Em complemento, o art. 27 dispunha que "a capacidade, ou incapacidade (art. 25) quanto a pessoas domiciliadas fora do Brasil, ou sejam estrangeiras ou nacionais, serão julgadas pela lei do respectivo domicílio, ainda que se trate de atos praticados no Império, ou de bens existentes no Império." Comentando essa opção, Teixeira de Freitas apoiou-se nitidamente em Savigny e sua teoria da sede das relações jurídicas, afirmando que "é o domicílio, e não a nacionalidade o que determina a sede jurídica das pessoas, para que se saiba quais as leis civis que regem a sua capacidade ou incapacidade". ${ }^{22}$

Em 1863, na primeira obra sobre Direito Internacional Privado publicada no Brasil, Pimenta Bueno defendeu também a lei da nacionalidade para a regência do estatuto pessoal, sustentando que "cada nacionalidade ou país tem o seu estatuto pessoal especial e apropriado, que acompanha os seus nacionais em toda e para toda e qualquer parte a que eles se dirijam". ${ }^{23}$

18 Grafia atualizada por mim. Utilizei o texto da terceira edição, de 1876, que foi republicado na Coleção "História do Direito Brasileiro - Direito Civil", com prefácio do Min. Ruy Rosado de Aguiar. FREITAS, Augusto Teixeira de. Consolidação das leis civis. 2 v. Prefácio de Ruy Rosado de Aguiar. — fac-símile da 3. ed. de 1876. Brasília: Senado Federal, 2003. A “Consolidação” possui uma introdução e ainda 1.333 artigos, fazendo a função de codificação do direito privado até a entrada em vigor do Código Civil em 1917.

19 Art. 35. "O estado e a capacidade civil das pessoas são regulados pelas leis da nação à qual elas pertencem (...)".

20 Art. 18. "O estado e a capacidade civil dos brasileiros, domiciliados ou residentes em país estrangeiro, são regulados pelas leis brasileiras, quanto aos atos que no Brasil tiverem de produzir os seus efeitos".

21 Grafia atualizada. Decreto n. 2.337, de 11 de janeiro de 1859, que aprovou o contrato com Augusto Teixeira de Freitas para a redação do projeto do Código Civil do Império. Disponível em: <http://www2.camara.leg. br/legin/fed/decret/1824-1899/decreto-2337-11-janeiro-1859-557246-publicacaooriginal-77587-pe.html>. Acesso em: 26 abr. 2015.

22 FREITAS, Augusto Teixeira de. Código civil: esboço. Rio de Janeiro: Ministro da Justiça e Negócios Interiores, 1952. (original de 1864).

23 Grafia atualizada. PIMENTA BUENO, José Antônio (Marquês de São Vicente). Direito internacional privado e applicação de seus principios com referencia ás leis particulares do Brazil. Rio de Janeiro: Typographia Imp. e Const. de J. Villeneuve \& C., 1863. p. 14. 
Na esfera governamental, a retórica do final do século XIX era o uso da regra da nacionalidade para atrair migrantes ao Brasil, que não precisariam temer a lei local. Eles “transportariam” sua própria lei para o Novo Mundo.

Esse argumento em prol da lei da nacionalidade foi explicitado pelo delegado brasileiro no Congresso de Direito Internacional Privado em Montevidéu de 1878, os debates sobre a elaboração de tratado de Direito Civil Internacional. A maioria dos delegados dos outros países defendeu a adoção da lei do domicílio para reger o estatuto pessoal. Já a delegação brasileira notabilizou-se por se opor ao projeto, pela defesa da lei da nacionalidade para reger a capacidade e personalidade. Os delegados dos demais países estavam conscientes do risco de falta de coerência e fragmentação da lei aplicável, se fossem adotadas as leis nacionais dos imigrantes. ${ }^{24}$

Contudo, para o Império brasileiro, na voz do Delegado Andrade Figueira, o princípio da nacionalidade seria um atrativo ao estrangeiro, que, sem ele, não seria estimulado a aceitar a imigração à América do Sul. ${ }^{25}$ Essa defesa retórica, sem base empírica e até contrária aos fatos (os demais Estados americanos adotaram a lei do domicílio e continuaram a receber migrantes) afastou o Brasil da codificação sul-americana da época.

\section{A lei da nacionalidade na República}

Já na República, o primeiro projeto solicitado a Coelho Rodrigues (entregue em 1893, mas rejeitado por comissão do Congresso) também adotou a lei da nacionalidade para a regência do estatuto pessoal (art. $13^{26}$ ).

$\mathrm{Na}$ época, a integração econômica do Brasil com a Europa, bem como a influência dos círculos acadêmicos europeus fez com que a onda a favor do uso da nacionalidade (adotada pelo Instituto de Direito Internacional e pela Conferência da Haia de Direito Internacional Privado) não fosse questionada no Brasil.

Por isso, o novo projeto de Código Civil, agora elaborado por Clóvis Beviláqua, seguiu a tradição imperial, tendo disposto no art. 22 que "a lei nacional da pessoa rege a sua capacidade e seus direitos de família".

Narram Espínola e Espínola Filho que poucos juristas brasileiros envolvidos na revisão do projeto Beviláqua antes de sua aprovação final pelo Congresso brasileiro

\footnotetext{
24 NOLDE, Boris. La codification du droit international privé. Recueil de Cours de l'Académie de Droit International de La Haye, v. 55, p. 299-432, 1936. p. 303-430, em especial p. 356.

25 Ver a exposição dos argumentos do delegado brasileiro Andrade Figueira em ESPÍNOLA, Eduardo; ESPÍNOLA FILHO, Eduardo. Tratado de direito civil brasileiro. Do direito internacional privado brasileiro - parte especial. Rio de Janeiro: Freitas Bastos, 1942. t. 1, v. 8, p. 189.

26 Art. 13. "O estado e a capacidade das pessoas, assim como os seus direitos de família, são regidos pela lei nacional das mesmas pessoas".
} 
apoiaram a adoção da lei do domicílio (a favor da lex domicilii estavam Costa Barradas e Bulhões de Carvalho ${ }^{27}$ ).

$\mathrm{Na}$ defesa da lei da nacionalidade, Beviláqua apelou, entre outros argumentos, ao vínculo entre o Estado e seu nacional do Direito Internacional Público, sustentando que essa emanação protetora também deveria ser utilizada no DIPr: “(...) O estatuto pessoal, isto é, o conjunto das relações de direito que se agrupam, sob o domínio da lei pessoal, deve ser a emanação protetora do Estado a que o individuo pertence e não a do país onde o individuo se acha". ${ }^{28}$

Os debates na Câmara e no Senado no bojo da aprovação do projeto de Código Civil no início da República foram, por anos, acirrados, com uma minoria de parlamentares advertindo sobre o risco da adoção da lei da nacionalidade em um país em nítida onda de recebimento de imigrantes europeus.

Entre os parlamentares, Carlos Maximiliano, elogiando Teixeira de Freitas, defendeu sem sucesso a modificação do projeto de Código Civil com a adoção da lei do domicílio: "Um país de imigração reclama a aplicação e o predomínio da lei do domicílio. Ciência imperfeita, o direito internacional privado não poderá deixar de ser particularista e função do direito público interno". ${ }^{29}$

Findo o longo debate, a lei da nacionalidade prevaleceu na introdução

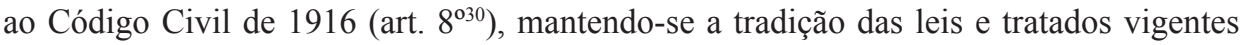
desde o Império, com a ressalva do uso subsidiário da lei do domicílio, caso a pessoa não possuísse nacionalidade (apátrida - art. $9^{\circ}$ ). No caso dos polipátridas, sendo uma delas a nacionalidade brasileira, deveria ser utilizada a lei brasileira. ${ }^{31}$

Em 1928, o Código Bustamante (Convenção Panamericana de Direito Internacional Privado ${ }^{32}$ ) buscou a conciliação para pacificar o "cisma" entre os defensores da lei do domicílio e os da lei da nacionalidade. Seu art. $7^{\circ}$ dispunha que "Cada Estado contratante aplicará como leis pessoais as do domicílio, as da nacionalidade ou as que tenha adotado ou adote no futuro a sua legislação interna". Assim, foi adotada a fórmula

27 ESPÍNOLA, Eduardo; ESPÍNOLA FILHO, Eduardo. Tratado de direito civil brasileiro. Do direito internacional privado brasileiro - parte especial. Rio de Janeiro: Freitas Bastos, 1942. t. 1, v. 8, p. 194.

28 BEVILÁQUA, Clóvis. Princípios elementares de direito internacional privado. 1. ed. Salvador: Livraria Magalhães, 1906. p. 146. Com atualização da redação em português.

29 Os debates parlamentares que antecederam a aprovação do Projeto Beviláqua foram reproduzidos com minúcias em ESPÍNOLA, Eduardo; ESPÍNOLA FILHO, Eduardo. op. cit., t. 1, v. 8, p. 254.

30 Art. 8. A lei nacional da pessoa determina a capacidade civil, os direitos de família, as relações pessoais dos cônjuges e o regime dos bens no casamento, sendo lícito quanto a este a opção pela lei brasileira.

31 Art. 9. Aplicar-se-á subsidiariamente a lei do domicílio e, em falta desta, a da residência: I. Quando a pessoa não tiver nacionalidade. II. Quando se lhe atribuírem duas nacionalidades, por conflito, não resolvido, entre as leis do país do nascimento, e as do país de origem; caso em que prevalecerá, se um deles for o Brasil, a lei brasileira.

32 Ratificado pelo Brasil e incorporado internamente pelo Decreto n. 18.871, de 13 de agosto de 1929. 
neutra de "lei pessoal", podendo cada Estado escolher a regra de conexão que considerasse mais apropriada. Contudo, com essa opção conciliatória, o Código Bustamante tornou-se inócuo, pois não resolveu a mais séria divergência do Direito Internacional Privado da época, que era a escolha entre a lei da nacionalidade e a lei do domicílio. ${ }^{33}$

\section{A adoção da lei do domicílio no Estado Novo getulista}

A manutenção da lei da nacionalidade no Império e nas primeiras décadas da República teve impacto indisfarçável na explosão do número de casos de aplicação da lei estrangeira no Brasil. O Direito Internacional Privado foi extremamente impulsionado, pois em diversas regiões do Brasil os imigrantes eram maioria em diversas comunidades.

Com a queda da República Velha, em 1930, Getúlio Vargas iniciou o processo de revisão do ordenamento jurídico brasileiro, para adaptá-lo às necessidades de um novo Brasil industrial, mas dentro da lógica autoritária e centralizadora que marcou todo o seu período no poder (1930-1945 34).

Para tanto, foi criada, por intermédio do Decreto n. 19.459, de 6 de dezembro de 1930, uma Comissão Legislativa para elaborar anteprojetos que renovassem totalmente o Direito brasileiro. O Ministro da Justiça, Oswaldo Aranha, foi feito presidente da Comissão, sendo a $1^{\text {a }}$ Subcomissão justamente a encarregada da revisão do Código Civil, sendo nomeados Clóvis Beviláqua, Eduardo Espínola e Alfredo Bernardes da Silva. No que tange ao Direito Internacional Privado, Eduardo Espínola foi o encarregado de fazer a revisão da parte introdutória do Código Civil.

Houve divergência na Subcomissão sobre a lei de regência do estatuto pessoal das pessoas físicas. De um lado, Eduardo Espínola defendeu a adoção da lei do domicílio, o que implicaria no uso da lei brasileira aos estrangeiros domiciliados aqui. Para dar contorno prático à inovação, Espínola usou os dados sobre entrada de estrangeiros no Brasil, demonstrando que, de 1918 a 1920, houve o ingresso de mais de um milhão de estrangeiros no país. Demonstrando a importância dessa massa de imigrantes, basta lembrar que, em 1920, a população total do Brasil atingiu aproximadamente 30 milhões de habitantes. ${ }^{35}$ Por outro lado, Beviláqua na Comissão defendeu a opção constante no Código

33 TENÓRIO, Oscar. Direito internacional privado. 11. ed. Rio de Janeiro: Freitas Bastos, 1976. v. 1, p. 415.

34 Nesse período, foi estabelecida a base da moderna Administração Pública brasileira, com a criação do DASP (Departamento Administrativo do Serviço Público, 1938), bem como pilares do ordenamento, como, por exemplo: Código de Processo Civil (1939), Código Penal (1940), Lei de Falências (1940), Código de Processo Penal (1941) e a Consolidação das Leis Trabalhistas (1943).

35 ESPÍNOLA, Eduardo; ESPÍNOLA FILHO, Eduardo. Tratado de direito civil brasileiro. Rio de Janeiro: Freitas Bastos, 1939. v. 2, p. 560. Sobre o Censo de 1920, ver dado do IBGE. Disponível em: <http:// www12.senado.leg.br/noticias/entenda-o-assunto/censo-demografico >. Acesso em: 25 jan. 2015. 
Civil de 1916 (lei da nacionalidade) que seria uma "tradição do nosso Direito". ${ }^{36}$ Para Eduardo Espínola, era indispensável essa mudança radical, pois "nos países de imigração as vantagens são do princípio do domicílio, para que a lei territorial se aplique ao grande número de estrangeiros, que venham neles exercer sua atividade civil ou comercial. $\mathrm{O}$ elemento territorial da lei deve então desenvolver toda a sua força de universalidade e, por evidente utilidade política, preponderar sobre o elemento pessoal". ${ }^{37}$ Esse anteprojeto de Lei de Introdução do Código Civil foi descartado pelo governo Vargas, tendo sido publicado, com sua justificativa, por Espínola e seu filho, em 1939. ${ }^{38}$

Por sua vez, após a edição da Constituição de 1937, o então Ministro da Justiça, Francisco Campos, nomeou uma comissão com a missão de elaborar um projeto de reforma do Código Civil de 1916, bandeira assumida por Getúlio Vargas, então Presidente da República. A comissão foi composta por Orozimbo Nonato, Philadelpho Azevedo, e pelo Consultor-Geral da República à época, Hahnemann Guimarães.

A aplicação, por décadas, do direito estrangeiro em diversas regiões de imigrantes no Brasil contrariava as ambições nacionalistas e autoritárias da Ditadura Vargas, que buscava impulsionar a industrialização nacional, com substituição das importações e ainda impunha restrições a novas ondas de imigrações estrangeiras, na busca de salvaguarda de mercado ao trabalhador brasileiro. ${ }^{39}$ Esse ambiente de modernização conservadora do Brasil gerou impacto no ordenamento jurídico e um dos alvos foi justamente a parte introdutória do Código Civil. Assim, foi adotada a reforma da introdução ao Código Civil pela edição do Decreto-Lei n. 4.657, de 4 de setembro de 1942, em vigência até hoje. Esse Decreto-Lei foi denominado "Lei de Introdução ao Código Civil" (LICC), uma vez que revogava a "Introdução" do Código Civil de 1916 (arts. $1^{\circ}$ ao 21). A nova LICC tratou de (i) normas de aplicação do direito (art. $1^{\circ}$ ao $6^{\circ}$ ) e (ii) normas de Direito Internacional Privado (arts. $7^{\circ}$ ao 19). No tocante ao estatuto pessoal, foi adotada finalmente a lei do domicílio em substituição à lei da nacionalidade.

Assim, somente em 1942, o Brasil curvou-se ao já adotado nos demais países receptores de mão de obra migrante nas Américas e implantou a regra da lei do domicílio (lex domicilii).

36 ESPÍNOLA, Eduardo; ESPÍNOLA FILHO, Eduardo. Tratado de direito civil brasileiro. Rio de Janeiro: Freitas Bastos, 1939. v. 2, p. 559.

37 Id. Ibid., p. 558.

38 Id. Ibid.

39 Sobre a xenofobia e restrições a estrangeiros na Ditadura Vargas, ver CARVALHO RAMOS, André de. Direitos dos estrangeiros no Brasil: a imigração, direito de ingresso e os direitos dos estrangeiros em situação irregular. In: SARMENTO, Daniel; IKAWA, Daniela; PIOVESAN, Flávia. (Org.). Igualdade, diferença e direitos humanos. Rio de Janeiro: Lumen Juris, 2008. p. 721-745. 
Para Valladão, a promulgação da LICC foi feita de modo apressado, tendo como razão imediata a entrada do Brasil na $2^{\mathrm{a}}$ Guerra Mundial, ocorrida poucos dias antes, em 22 de agosto de 1942.

A motivação da sua edição teria sido substituir a regra da lei da nacionalidade da antiga introdução ao Código Civil de 1916 pela da lei do domicílio, para não se aplicar o Direito estrangeiro aos nacionais do Eixo, da Alemanha e da Itália (agora súditos inimigos), que eram aqui domiciliados em virtude da forte imigração nas décadas anteriores. $^{40}$

Foi criticada a falta de debate e secretismo envolvendo a lei ("obra legislativa clandestina", para Valladão ${ }^{41}$ ), uma vez que a Comissão só realizou uma única reunião oficial, em 1940, na qual constou que outras reuniões anteriores, tendo sido elaborada o projeto de lei de introdução já em 1939.

Do ponto de vista formal, houve uma fundamental mudança: a Comissão entendeu, acertadamente, que os dispositivos analisados não deveriam fazer parte do Código Civil e sim constar de uma lei autônoma, merecendo uma legislação especial.

O domicílio é, então, o lugar da sede ou centro de suas relações intersubjetivas de um indivíduo, regendo sua personalidade e capacidade. Valladão criticou a adoção, de modo unitário e universal, da lei do domicílio para reger o estatuto pessoal, uma vez que os direitos de personalidade (em especial o direito ao nome) deveriam ser regidos, para a segurança e proteção do indivíduo, pela lei da nacionalidade, ou, ao menos, pela lei do lugar do registro. ${ }^{42}$

Ocorre que os direitos envolvendo o estatuto pessoal são regidos de acordo com a lei do domicílio do momento do exercício de determinado direito (momento do ato, na denominação de Valladão ${ }^{43}$ ). Além disso, é possível a invocação de direitos adquiridos para a proteção do nome, além da aplicação da cláusula de ordem pública informada pela proteção de direitos humanos, para evitar eventuais violações de direitos causada pela lei do domicílio.

A definição do que vem a ser domicílio é feita pela lex fori, na ausência de convenção específica sobre o tema, uma vez que tal definição recai na esfera da qualificação, e o art. $7^{\circ}$ da LINDB não faz a remissão à lex causae, como há nos arts. $8^{\circ}$ e $9^{\circ}$.

\footnotetext{
40 VALLADÃO, Haroldo. A lei de introdução ao código civil e sua reforma. Revista dos Tribunais, v. 49, n. 292, p. 7-21, fev., 1960. Em especial p. 7.

41 Valladão chegou, inclusive, a sustentar o que denominou "desleixo com que foi, assim, promulgada a Lei de Introdução". Id. Ibid., em especial p. 7-8.

42 VALLADÃO, Haroldo. Direito internacional privado. 2. ed. Rio de Janeiro: Freitas Bastos, 1977. v. 2, p. 13.

43 Id. Ibid., p. 19.
} 
O Código Bustamante aponta para sistema distinto, escolhendo o critério territorial. E seu art. 22 dispõe que o conceito, aquisição e reaquisição do domicílio geral e especial das pessoas físicas ou jurídicas são regidos pela lei territorial. ${ }^{44}$ Para Serpa Lopes, essa lei territorial seria a lei do Estado em cujo solo se encontra o citado domicílio. ${ }^{45}$ Esse sistema aproxima-se da definição do domicílio pela lex causae.

No caso do sistema da lex fori (predominante, na exceção de convenção internacional que disponha diferentemente ${ }^{46}$ ), é útil a análise do que estabelece a lei brasileira. No Brasil, o domicílio da pessoa física consiste na "sede jurídica da pessoa, onde ela se presume presente para efeitos de direito e onde pratica habitualmente seus atos, e negócios jurídicos". ${ }^{47}$

$\mathrm{Na}$ mesma linha, Beviláqua sustenta que o domicílio da pessoa física é o lugar onde ela, de modo definitivo, estabelece a sua residência e o centro principal da sua atividade. ${ }^{48} \mathrm{O}$ Código Civil brasileiro é expresso ao definir o domicílio da pessoa natural, no art. 70, como sendo "o lugar onde ela estabelece a sua residência com ânimo definitivo".

Assim, há dois elementos que são exigidos para a fixação do domicílio da pessoa natural: (i) o elemento objetivo, que é a residência, ou seja, o estado de fato referente à moradia ou permanência da pessoa; (ii) o elemento subjetivo, referente ao componente psicológico que é o ânimo de fixar-se de modo permanente. O Código Civil admite a pluralidade de domicílios, no caso da pessoa natural possuir diversas residências, onde, alternadamente, viva. ${ }^{49}$

Também foi aceita outra hipótese de domicílio plúrimo, que é o domicílio profissional, determinando o art. 72 do CC que é também domicílio da pessoa natural, quanto às relações concernentes à profissão, o lugar onde esta é exercida.

Para fins do DIPr, há apenas um domicílio, o que gera o problema da determinação do domicílio em duas situações: (i) mais de um domicílio e (ii) ausência de domicílio.

44 Art. 22. O conceito, acquisição, perda e reacquisição do domicilio geral e especial das pessoas naturaes ou jurídicas reger-se-ão pela lei territorial.

45 SERPA LOPES, Miguel Maria de. Comentários à lei de introdução ao código civil. 2. ed. Rio de Janeiro: Freitas Bastos, 1959. v. 2, p. 22-23.

46 Por exemplo, a Convenção Interamericana sobre Domicílio das Pessoas Físicas no Direito Internacional Privado de 1979, ainda não ratificada pelo Brasil.

47 MONTEIRO, Washington de Barros. Curso de direito civil: parte geral. 38. ed. São Paulo: Saraiva, 2001. p. 136.

48 BEVILÁQUA, Clóvis. Teoria geral do direito civil. 2. ed. atual. e rev. por Caio Maio da Silva Pereira. Rio de Janeiro: Livraria Francisco Alves, 1976.

49 Código Civil brasileiro, art. 71: "Se, porém, a pessoa natural tiver diversas residências, onde, alternadamente, viva, considerar-se-á domicílio seu qualquer delas”. 
No que tange à pluralidade de domicílios, o que é aceito no Brasil, como visto acima, a solução implícita que se extrai da LINDB é o uso da lei de cada domicílio para os atos e relações jurídicas lá realizadas.

Já quando à ausência de domicílio, o $\S 8^{\circ}$ do art. $7^{\circ}$ da LINDB prevê explicitamente a solução para tais situações, pelo uso de regra de conexão sucessiva: em primeiro lugar, usa-se a lei da residência habitual. A residência habitual consiste aquela morada de uso contínuo, mesmo sem o ânimo definitivo. Basta para sua caracterização o elemento objetivo da definição de domicílio, ou seja, o elemento de moradia ou estadia de uma pessoa.

Após, caso esta não seja identificada, a lei do lugar onde a pessoa se encontre. Há o risco da regra da conexão sucessiva, que poderia levar a uma espécie de "manipulação da lei" pelo indivíduo especialmente na hipótese da invocação da lei do lugar onde a pessoa se encontre.

A Convenção Interamericana sobre Domicílio das Pessoas Físicas em Direito Internacional Privado (Montevidéu, 197950) atualizou a matéria. De acordo com o art. $2^{\circ}$, o domicílio de uma pessoa física é determinado pelas seguintes regras de conexão sucessivas: 1) lei do lugar da residência habitual; 2) lei do lugar do centro principal dos seus negócios; 3) lei do lugar da simples residência; 4) lei do lugar onde se encontra. Nota-se a vontade de se eliminar as dúvidas sobre a conceituação de "domicílio". A regra de conexão principal considera domicílio o "lugar da residência habitual". Evita-se a indagação do ânimo do agente, constante da definição brasileira (art. 70 do CC, 2002 ${ }^{51}$ ) sobre ser o domicílio a residência com ânimo definitivo. Contudo, a Convenção ainda não foi ratificada pelo Brasil.

Quanto aos casos especiais, é possível suprir as lacunas da LINDB.

1) Incapazes. O domicílio das pessoas incapazes será o dos seus representantes legais, salvo no caso de abandono de tais pessoas pelos referidos representantes, caso esse em que continuara vigendo o domicílio anterior.

2) Pessoas casadas. O domicílio dos cônjuges será aquele em que vivam de comum acordo, sem prejuízo do direito de cada cônjuge de fixar seu domicílio de acordo com a regra de conexão sucessiva, já estudada.

3) Diplomatas e Cônsules. O domicílio dos agentes diplomáticos e consulares será o último que tiverem tido no território do Estado acreditante.

\footnotetext{
50 Assinada pelo Brasil, mas ainda não ratificada até a data de fechamento da edição (março de 2015).

51 Art. 70. O domicílio da pessoa natural é o lugar onde ela estabelece a sua residência com ânimo definitivo.
} 
5. O estatuto pessoal nos projetos após a LICC de 1942

Após a LICC varguista, houve iniciativas de atualização e sistematização das normas de Direito Internacional Privado, que, contudo, fracassaram. Dois projetos não aprovados merecerem destaque: (i) o originado no anteprojeto de 1964, de Haroldo Valladão, denominado Lei Geral de Aplicação de Normas Jurídicas e o (ii) Projeto de Lei n. 4.905/95.

No primeiro caso, o anteprojeto era completo e visava a substituição do modelo de "Lei de Introdução ao Código Civil" para tratar do DIPr. O anteprojeto ambicionava a aprovação de uma "Lei Geral de Aplicação das Normas Jurídicas", pois, segundo o autor, a denominação "Lei de Introdução ao Código Civil" é inapropriada, vez que tal diploma se refere ao direito pátrio como um todo e não apenas ao Código que introduz..$^{52}$ Possuía 91 artigos e não se restringia a regulação da aplicação espacial da lei de direito privado, abrangendo, também, relações de trabalho, direito marítimo e aéreo, direitos de autor, direito cambial e de propriedade intelectual, jurisdição e cooperação jurídica internacional. Seu art. 16 era emblemático e previa um novo Direito Internacional Privado de objeto amplo muito além de uma introdução ao Código Civil. Para Valladão, "aplicam-se, de forma direta ou indireta, normas de direito brasileiro no exterior e de direito estrangeiro no Brasil com o fim de assegurar a continuidade espacial da vida jurídica das pessoas, em virtude de regras de direito internacional privado (...)".

Em 1970, o anteprojeto foi ligeiramente alterado pela Comissão Revisora, formada por Luiz Gallotti, do Supremo Tribunal Federal, pelos Professores Oscar Tenório e Valladão, recebendo a denominação de "Código de Aplicação das Normas Jurídicas" e passando a conter 93 artigos. Foi introduzido, por sugestão de Oscar Tenório, dispositivo de coordenação com os tratados de DIPr, pelo qual "os preceitos dos artigos anteriores aplicam-se, no que couber, sem prejuízo de convenções internacionais ratificadas pelo Brasil". ${ }^{3}$

A regência do estatuto pessoal foi tratada no projeto de Código de Aplicação das Normas Jurídicas (anteprojeto de Haroldo Valladão somadas as alterações da Comissão Revisora) nos arts. 22 e seguintes. De acordo com o art. 22, a existência e $o$ reconhecimento da personalidade regem-se segundo o direito brasileiro. Já o art. 24 estipulava que os direitos da personalidade, inclusive o nome, serão protegidos segundo o direito brasileiro. Por sua vez, o art. 26 dispunha que as incapacidades por impossibilidade

52 VALLADÃO, Haroldo. Lei geral de aplicação das normas jurídicas. Revista da Faculdade de Direito da Universidade de São Paulo, São Paulo, v. 60, p. 121-131, 1965. Em especial p. 125.

53 Texto integral e ainda exposição de Valladão sobre seu anteprojeto, bem como relatório da comissão revisora constam de VALLADÃO, Haroldo. Direito internacional privado. Direito intertemporal, introdução e história do direito. Material de classe. 9. ed. Rio de Janeiro: Freitas Bastos, 1977. p. 108-169. 
física ou moral de agir e dependência de representação ou assistência necessárias regemse segundo a lei do domicílio da pessoa ao tempo do ato. Ainda, para o Código, não seria nulo o ato de direito das obrigações realizado no Brasil se o agente fosse capaz pela lei brasileira $\left(\S 1^{\circ}\right.$ do art. 26). Por seu turno, o art. $26 \S 2^{\circ}$ previu o impacto da transferência de domicílio, estipulando que, se a pessoa mudasse de domicílio, permaneceria capaz (se já o era) ou tornar-se-ia capaz, se o fosse a ser pela lei brasileira. ${ }^{54}$ Esse projeto, então, seguiu a visão de Valladão, para quem o cerne do estatuto pessoal era a definição da personalidade e, esta, só poderia ser regulada pela lex fori (a lei brasileira, no caso).

Em 1994, foi realizada outra iniciativa de reforma da Lei de Introdução ao Código Civil de 1942 por comissão composta pelos Professores Rubens Limongi França, João Grandino Rodas (ambos da Universidade de São Paulo), Inocêncio Mártires Coelho (Universidade de Brasília) e Jacob Dolinger (Universidade Estadual do Rio de Janeiro), que redundou no Projeto de Lei n. 4.905/1995. O projeto era sensivelmente menos ambicioso do que o anteprojeto Valladão, contendo apenas 25 artigos (a LINDB atualmente em vigor possui 19 artigos).

Buscava, primeiramente, em um contexto de reformas do Governo Fernando Henrique Cardoso (1994-2002), o reforço da autonomia da vontade, em uma visão de estímulo à segurança jurídica de investidores estrangeiros. Ponto positivo foi a introdução, no Capítulo III ("Direito Internacional Privado"), de uma seção específica para "Cooperação Jurídica Internacional”, apesar de limitada as duas espécies tradicionais (carta rogatória e ação de homologação de sentença estrangeira).

No tocante ao estatuto pessoal, o Projeto de Lei n. 4.905/95 estipulava, em seu art. $8^{\circ}$ (denominado de «Estatuto Pessoal") que a personalidade, o nome, a capacidade e os direitos de família são regidos pela lei do domicílio. Ante a inexistência de domicílio ou na impossibilidade de sua localização, deveriam ser aplicadas, sucessivamente, a (i) lei da residência habitual e a (ii) lei da residência atual. Também dispunha o projeto que as crianças, os adolescentes e os incapazes seriam regidos pela lei do domicílio de seus pais ou responsáveis; tendo os pais ou responsáveis domicílios diversos, seria utilizada a lei que resulte no melhor interesse da criança, do adolescente ou do incapaz. Assim, houve aperfeiçoamento na regência do estatuto pessoal, sendo feita inclusive a opção pelo "better law approach", ao menos no que tange ao melhor interesse da criança e adolescente. Também esse projeto não foi aprovado.

Atualmente, continua em trâmite o Projeto de Lei do Senado Federal n. 269, apresentado em 2004, pelo Senador Pedro Simon, que consiste em reapresentação do Projeto de Lei n. 4.905/95, com alterações pontuais. Não obstante o esforço para

54 VALLADÃO, Haroldo. Direito internacional privado. Direito intertemporal, introdução e história do direito. Material de Classe. 9. ed. Rio de Janeiro: Freitas Bastos, 1977. p. 108-169, em especial p. 154. 
modernização e atualização da legislação conflitual brasileira, nenhum dos projetos de lei para a substituição da LICC de 1942 chegou a ser aprovado.

\section{Conclusão}

O cisma entre a lei da nacionalidade e a lei do domicílio já foi ironizado por Valladão como sendo a versão do DIPr do embate entre os verdes e os azuis em Bizâncio. ${ }^{55}$

Esse cisma parte da premissa de que uma das duas opções (lei da nacionalidade ou lei do domicílio) é a solução uniforme para todas as querelas e disputas oriundas do estatuto pessoal. Porém, como o estudo de De Winter demonstrou, ambas as regras de conexão passaram por forte crise no século $X X{ }^{56} \mathrm{~A}$ regra da nacionalidade foi erodida pelos fortes fluxos de pessoas gerados pelas guerras mundiais, com alterações territoriais em diversos países, gerando perda de nacionalidade e dúvida sobre a nacionalidade de determinada pessoa. Além disso, os novos fluxos de pessoas baseados em demandas sociais (migrantes econômicos) aumentaram a diversidade de nacionalidades em um determinado Estado, elevando a possibilidade da existência de "quistos" de direito estrangeiro, caso a regra da nacionalidade fosse mantida. Outro fator de aumento do receio de permanência longeva de nichos de direito estrangeiro em um Estado foi a igualdade de gênero trazida pelo Direito Internacional dos Direitos Humanos, o que fez com que a mulher não mais perdesse sua nacionalidade originária pelo casamento.

Por outro lado, a lei do domicílio também foi alvo de questionamentos, pelas diferenças de qualificação entre os Estados (inclusive entre os da vertente da "civil law" e os da "common law" ${ }^{57}$ ) e dificuldade de se determinar o "ânimo" definitivo trazido por inúmeras legislações (inclusive a brasileira).

Surgiu na Conferência da Haia sobre Direito Internacional Privado a alternativa da fixação de critério alternativo baseado na residência habitual, sendo pioneiros os tratados sobre guarda de menores e adultos de 1902 e 1905. Em 1956, a Convenção sobre a Lei Aplicável a Obrigações Alimentícias com Relação aos Filhos consagrou a regra de conexão da residência habitual da criança. Obviamente, podem existir dúvidas sobre como definir a habitualidade da residência, o que fez De Winter defender a prova

\footnotetext{
55 VALLADÃO, Haroldo. Lei Nacional e Lei do Domicílio. In: Estudos de Direito Internacional Privado. Rio de Janeiro: José Olympio, 1947. p. 186-201, em especial p. 186.

56 DE WINTER, L. I. Nationality or domicile? The present state of affairs. Recueil des Cours de l'Académie de Droit International de La Haye, v. 128, p. 347-504, 1969.

57 Conferir em CAVERS, David F. Habitual Residence: A Useful Concept? American University Law Review, v. 21, p. 475-493, 1972. Em especial p. 477.
} 
de integração social da pessoa com o local da residência ("social domicile"). Para o autor, a melhor lei para o estatuto pessoal é a lei da comunidade a qual o indivíduo pertence. ${ }^{58}$

Influenciada pela tendência de superação do domicílio e da nacionalidade, a Convenção Interamericana sobre domicílio das pessoas físicas no Direito Internacional Privado (1979) escolheu a lei do lugar da residência habitual como seu principal critério de conexão $\left(\operatorname{art} .2^{\circ}\right)$.

Além dos problemas referentes à nacionalidade e domicílio, constato que a abrangência das matérias inseridas no rótulo do "estatuto pessoal" pode levar à necessidade de escolha de critério de conexão flexível, como, por exemplo, o relacionado ao princípio da proximidade (também chamado de princípio do vínculo mais estreito), pelo qual deve ser aplicada a lei do Estado que for o mais próximo do fato transnacional.

Para Valladão, não é possível adotar uma concepção unitária e genérica de "estatuto pessoal" ou "lei pessoal", disciplinando-o com um critério único (lei nacional ou o da lei do domicílio), mas sim é necessário adotar um princípio solucionador do conflito justo e equitativo a cada relação jurídica. ${ }^{59}$

Nessa linha, o princípio da proximidade ou da conexão mais estreita pode substituir a tradicional polêmica, porque consiste no reconhecimento de que não há fórmula rígida a definir uma regra de conexão, devendo ser escolhida a lei que seja a mais apropriada em virtude das características da relação jurídica. Pillet, no início do século $\mathrm{XX}$, defendeu o uso da flexibilidade na definição da lei de regência do estatuto pessoal. Para o autor, «(...) Même lorsque les personnes dont il s'agit ont une patrie commune, il paraît plus naturel de leur prêter l'intention de soumettre leurs accords à la loi de leur domicile commun». ${ }^{60}$

Assim, à guisa de conclusão, a regência do estatuto pessoal não pode ficar aprisionada na luta ultrapassada entre a lei da nacionalidade e a lei do domicílio. O estudo de caso por caso pode facilitar novas propostas e mesmo a adoção de critérios mais flexíveis de invocação da lei estrangeira ao caso transnacional.

São Paulo, 30 de abril de 2015.

\footnotetext{
58 DE WINTER, L. I. Nationality or domicile? The present state of affairs. Recueil des Cours de l'Académie de Droit International de La Haye, v. 128, p. 347-504, 1969. Em especial p. 431.

59 VALLADÃO, Haroldo. Lei reguladora do estatuto pessoal. Revista Forense, Rio de Janeiro, v. 51, n. 153, p. 503-513, maio/jun., 1954.

${ }_{60}$ PILLET, Antoine. Principes de droit international privé. Paris: Pedone/Allier Frères, 1903. Em especial p. 441.
} 


\section{Referências}

BARBOSA DE MAGALHAES, José Maria. La doctrine du domicile en droit international privé. Recueil des Cours de l'Académie de Droit International de La Haye, v. 23, p. 1-144, 1928.

BENTWICH, N. Le développement récent du principe du domicile en droit anglais. Recueil des Cours de l'Académie de Droit International de La Haye, v. 49, p. 373-468, 1934.

BEVILÁQUA, Clóvis. Principios elementares de direito internacional privado. 1. ed. Salvador: Livraria Magalhães, 1906.

BEVILÁQUA, Clóvis. Teoria geral do direito civil. 2. ed. atual. e rev. por Caio Maio da Silva Pereira. Rio de Janeiro: Livraria Francisco Alves, 1976.

BOYE, A. K. Le statut personnel dans le droit international privé des pays africains au sud du Sahara. Conceptions et solutions des conflits de lois. Le poids de la tradition négro-africaine personnaliste. Recueil des Cours de l'Académie de Droit International de La Haye, v. 238, p. 247-420, 1993.

CARVALHO RAMOS, André de. Direitos dos estrangeiros no Brasil: a imigração, direito de ingresso e os direitos dos estrangeiros em situação irregular. In: SARMENTO, Daniel; IKAWA, Daniela; PIOVESAN, Flávia. (Org.). Igualdade, diferença e direitos humanos. Rio de Janeiro: Lumen Juris, 2008. p. 721-745.

CARVALHO RAMOS, André de. Direito internacional privado e a ambição universalista. In: TIBURCIO, Carmen; VASCONCELOS, Raphael; MENEZES, Wagner. Panorama do direito internacional privado atual e outros temas contemporâneos. Festschrift ao Professor Jacob Dolinger. Belo Horizonte: Arraes, 2015. p. 14-33.

CARVALHO RAMOS, André de. Evolução histórica do direito internacional privado e a consagração do Conflitualismo. Revista de la Secretaría del Tribunal Permanente de Revisión, a. 3 , n. 5, p. 423-446, Marzo 2015.

CASSIN, René. La nouvelle conception du domicile dans le règlement des conflits de lois. Recueil des Cours de l'Académie de Droit International de la Haye, v. 34, p. 659-809, 1930.

DE WINTER, L. I. Nationality or domicile? The present state of affairs. Recueil des Cours de l'Académie de Droit International de La Haye, v. 128, p. 347-504, 1969.

ESPÍNOLA, Eduardo; ESPÍNOLA FILHO, Eduardo. Tratado de direito civil brasileiro. Do direito internacional privado brasileiro: parte especial. Rio de Janeiro: Freitas Bastos, 1942. t. 1, v. 8.

ESPÍNOLA, Eduardo; ESPÍNOLA FILHO, Eduardo. Tratado de direito civil brasileiro. Rio de Janeiro: Freitas Bastos, 1939. v. 2.

FREITAS, Augusto Teixeira de. Código civil: esboço. Rio de Janeiro: Ministro da Justiça e Negócios Interiores, 1952. (Original de 1864). 
FREITAS, Augusto Teixeira de. Consolidação das leis civis. Prefácio de Ruy Rosado de Aguiar. fac-símile da 3. ed. de 1876. Brasília: Senado Federal, 2003. 2 v.

GONÇALVES, Carlos Roberto. Direito civil brasileiro: parte geral. 10. ed. São Paulo: Saraiva, 2012. v. 1.

HOBSBAWM, Eric J. Nações e nacionalismo. 5. ed. São Paulo: Paz e Terra, 2008.

MANCINI, Pasquale S. A nacionalidade como fundamento do direito das gentes. (1851) In: Direito Internacional: coletânea. Ijuí: Ed. Unijuí, 2003.

NOLDE, Boris. La codification du droit international privé. Recueil de Cours de l'Académie de Droit International de La Haye, v. 55, p. 303-430, 1936.

PILLET, Antoine. Principes de droit international privé. Paris: Pedone/Allier Frères, 1903.

PIMENTA BUENO, José Antônio (Marquês de São Vicente). Direito internacional privado e applicação de seus principios com referencia ás leis particulares do Brazil. Rio de Janeiro: Typographia Imp. e Const. de J. Villeneuve \& C., 1863.

SAVIGNY, Friedrich Carl von. Sistema do direito romano atual. Tradução de Ciro Mioranga. Ijuí: Ed. Unijuí, 2004. v. 8. (Edição original de 1849).

SERPA LOPES, Miguel Maria de. Comentários à lei de introdução ao código civil. 2. ed. Rio de Janeiro: Freitas Bastos, 1959. v. 2.

VALLADÃO, Haroldo. A Lei de introdução ao código civil e sua reforma. Revista dos Tribunais, v. 49, n. 292, p. 7-21, fev. 1960.

. Conséquences de la différence de nationalité ou de domicile des époux sur les effets et la dissolution du mariage. Recueil des Cours de l'Académie de Droit International de La Haye, v. 105, p. 69-172, 1962.

- Lei geral de aplicação das normas jurídicas. Revista da Faculdade de Direito da Universidade de São Paulo, São Paulo, v. 60, p. 121-131, 1965.

. Direito internacional privado. Direito intertemporal, introdução e história do direito. Material de classe. 9. ed. Rio de Janeiro: Freitas Bastos, 1977.

. Direito internacional privado. 2. ed. Rio de Janeiro: Freitas Bastos, 1977. v. 2.

\section{4.}

. Lei reguladora do estatuto pessoal. Revista Forense, v. 51, n. 153, p. 503-513, maio/jun.,

VALLADÃO, Haroldo. Lei nacional e lei do domicílio. In: Estudos de Direito Internacional Privado. Rio de Janeiro: José Olympio, 1947. p. 186-201.

VILLELA, Álvaro da Costa Machado. Tratado elementar (teórico e prático) de direito internacional privado. Coimbra: Coimbra Editora, 1921. v. 1. 